\title{
THE CONCEPT OF MALE OUTCROSSING IN HERMAPHRODITE HIGHER PLANTS
}

\author{
AUGUSTE HOROVITZ* and JAMES HARDING
}

Department of Environmental Horticulture, University of California, Dovis

Received 8.xii.71

\section{INTRODUCTION}

Determinations of the reproductive mode in higher hermaphrodite plants are usually based on observations of seed parent performance. While a self-fertilising plant makes equal male and female gamete contributions to the next generation, so that male gamete contributions can be extrapolated from data on functional embryo sacs, this situation need not hold in outcrossing plants. Here the 1: 1 ratio between male and female gametes obtains only at the level of the population and individuals or gentoypes in the breeding entity can function more largely as male than as female parents, or vice versa, at each other's expense.

In partially self-fertilising plants this inequality can affect the outcrossing rate and in the present study such an effect is traced in the partially selfing California annual legume, Lupinus nanus Dougl. (ex. Benth.). The sporophytic outcrossing rate is usually measured in progeny tests by the frequency with which functional female gametes unite with male gametes produced by different sporophytes. For the purposes of the present study this rate is termed the female outcrossing rate. For the frequency with which functional male gametes unite with female gametes from a different sporophyte a separate estimator is derived and termed the male outcrossing rate.

Environmental and genetic influences on rates of outcrossing in partial selfers have been demonstrated in numerous investigations (see e.g. Stevens and Finkner, 1953; Harding and Tucker, 1964; Vasek, 1967). In Lupinus nanus it seemed plausible that outcrossing would be affected by flower colour and pattern. Evidence on visual responses in honey bees (Daumer, 1956; Menzel, 1967) and bumble bees (Manning, 1956) suggested that the lupine mutant genotypes pink and spotless (Harding and Mankinen, 1967; Horovitz, 1969) were likely to attract pollinating insects less efficiently and, therefore, outcross at lower rates than a blue-flowered wild-type form. Our purpose was to verify such outcrossing differences and relate them separately to male and female outcrossing phases of mutant and wild-type forms. The results of the study are used to predict possible evolutionary outcomes of natural selection among genotypes that differ in the sex balance of their outcrossing phase.

\section{ThEORETICAL MODEL}

The female outcrossing frequency, $\alpha$, of a given sporophyte is defined as the binomial probability of a resident female gamete uniting with a male

* Present address: Department of Botany, Tel-Aviv University, Tel-Aviv, Israel. 
gamete produced by a different sporophyte. Methods to measure male gametophytic selective values simultaneously with female outcrossing rates have been presented by Harding and Tucker (1969). The authors treat the selective value of one outcrossing gametophyte as a constant (arbitrarily set a unity) and accord selective values $m_{j}$ for the remaining outcrossing male gametophytes. With $m_{j}$ the frequency of genotypes in the outcrossing pollen pool can be estimated. The male outcrossing, $\beta$, of a given sporophyte is defined as the binomial probability for its male gametes to unite with female gametes produced on a different sporophyte. Thus, the reproductive mode of a specified sporophyte can be described from the standpoint of its male and female gametophytes.

In the present investigation bipartite populations in which two genotypes are mixed in equal proportions are used for the estimation of the parameters $\alpha$ and $m$. The expectations in terms of these parameters for selfing, homogeneous outcrossing, and heterogeneous outcrossing are shown in table 1.

TABLE 1

Bipartite population with genotypes $A$ and $B$ in equal frequency. In $A$ female outcrossing is equal to or lower than in $B$ and the male gametophytic selective value in $A$ equals $1 \cdot 0$

Parent genotypes

Progeny

Expected frequency

Observable frequency
A

$\begin{array}{ccc}\text { Case A-1 } & \text { Case A-2 } & \text { Case A-3 } \\ \text { Selfed } & \begin{array}{c}\text { Crossed to } \\ \text { A }\end{array} & \begin{array}{c}\text { Crossed to } \\ \text { B }\end{array}\end{array}$

$\mathrm{B}$

Case B-1 Case B-2 Case B-3

Selfed Crossed to Crossed to B A

In the simplest model of such a population, genotypes $\mathrm{A}$ and $\mathrm{B}$ are equally represented. The outcross-pollen frequency of form $\mathrm{A}$ is $1 /(m+1)$ and that of form B is $m /(m+1)$. Progenies from genotypes A and B are grown separately. With the aid of recessive markers two classes can be recognised in each progeny, namely $a$ and $(1-a)$ in first-generation offspring from $\mathrm{A}$, and $b$ and $(1-b)$ in that from $B$. With two degrees of freedom, two parameters can be estimated, viz. $m$ and $\alpha$. Where the estimated $\alpha$ is the female outcrossing frequency in $\mathrm{B}$, that in $\mathrm{A}$ is set at $k \alpha$. The constant $k$ must be estimated in auxiliary studies and substituted into this model. Parents are designated in such a way that $k$ lies between 0 and 1 .

Parameter $m$ can be estimated as the ratio of case A-3 to case B-3 (table 1); hence

$$
\hat{m}=a / k b,
$$

and

$$
\hat{\alpha}=(a \mid k)+b
$$

Male outcrossing frequencies in a genotype can be determined by adding the cases of outcrossing in which it acts as male parent and dividing these by the sum of all cases in which it acts as a pollen parent. $\beta_{A}$ can thus be read from table $\mathrm{I}$ as case A-2 plus case B-3 divided by case A-1 plus case A-2 plus case B-3, or

$$
\beta_{A}=\alpha(1+k) /[\alpha(1+k)+(1-k \alpha)(m+1)]
$$


Similarly, $\beta_{B}$ can be expressed as case A-3 plus case B-2 divided by case B-1 plus case A-3 plus case $\mathrm{B}-2$, or

$$
\beta_{B}=m \alpha(1+k) /[m \alpha(1+k)+(1-\alpha)(m+1)]
$$

\section{Experimental populations}

Outcrossing frequencies were studied in seven openly pollinated experimental populations of Lupinus nanus. These populations included the following homozygously marked genetic stocks:

G-41-wild-type blue, with spots, $P P C C$, and with seed-coat markers, II ee,

G-30-wild-type blue, with spots, $P P C C$, and recessive seed-coat markers, ii ee,

G-33-blue, spotless, $P P c c$,

G-2 and G-37-pink, with spots, $p p C C$, and dominant seed coat-markers, II EE; these two pink mutants were used interchangeably.

The stocks descend from wild collections in the Lake Berryessa area (Yolo County, California).

The populations were of two types. The first were bipartite populations composed of two genotypes with reciprocal genetic markers and with a mating pattern as that shown in table 1. For estimations of $\alpha$ and $m$ in these populations seed from each component genotype was sampled at periodic intervals. Each pair of samples represented an open-pollination test and yielded two separate progenies. In each progeny two phenotypic classes could be recognized, namely dominantly marked $a$ and $b$, respectively, from heterogeneous outcrosses and $(1-a)$ and $(1-b)$, respectively, from selfing plus homogeneous outcrosses. The bipartite populations, isolated from other plantings by about one mile, were:

Population 1-wild-type (G-30) and pink (G-37) mixed in equal proportions, planted in Davis, California, 1967,

Population 2-wild-type (G-30) and pink (G-2 + G-37) mixed in equal proportions, planted in Davis, 1968,

Population 3-wild-type (G-30) and pink (G-2 + G-37) mixed in equal proportions, planted in Berkeley, California, 1968, and

Population 4-wild-type (G-30) and spotless (G-33) mixed in equal proportions, planted in Davis, 1968.

The second set of populations were pollen-donor plantings, each composed of one genetic stock. They were used for auxiliary tests of the genotypes studied in bipartite populations, namely for independent estimations of female outcrossing, $\alpha$, and for determinations of the female outcrossing differential $k$. Single potted plants of the genetic stocks in which $\alpha$ was to be estimated, namely wild-type (G-30), pink (G-37, G-2), and spotless (G-33), were brought into flower in an insect-proof greenhouse, set out in the pollen-donor plantings for a few days, and then returned to the greenhouse. Specific flowers of different genetic stocks could thus be exposed to the same pollen donors simultaneously and were then progeny tested. Since the tested female parents carried recessive markers at loci at which the pollen donor was dominant, dominant phenotypes in their progenies indicated outcrosses. The pollen donor populations were: 
Population 5-a uniform planting of wild-type G-41, planted in Davis, 1968,

Population 6-another uniform planting of wild-type G-41 located 250 feet from Population 5, and

Population 7-a uniform planting of the pink mutant (G-2 + G-37), located between Populations 5 and 6.

Few pollinating bees, rarely more than two or three, were observed simultaneously foraging on a plot. In Davis where a bee hive was placed in each population these were mainly honey bees; next in frequency was Anthophora urbana. In Berkeley bumble bees were seen most frequently.

\section{EXPERIMENTAL RESULTS}

Before the bipartite populations could be analysed, $k$ values were determined from female outcrossing estimates for genetic stocks obtained in Populations 5 and 6 . These estimates are quite free of bias from male gametophytic selection, because the pollen pool was experimentally set so near the limiting frequency of 1.0 for the dominantly marked male gametes. The combined results (table 2) from different sampling dates through the

TABLE 2

Estimates of female outcrossing for genetic stocks tested in Populations 5 and 6

\begin{tabular}{lccc}
\multicolumn{1}{c}{ Genetic stock } & Flower colour & $\hat{\alpha}$ & $\sigma_{\hat{\alpha}}{ }^{*}$ \\
G-30 & Blue & 0.483 & 0.016 \\
G-37 & Pink & 0.424 & 0.043 \\
G-2 & Pink & 0.573 & 0.032 \\
G-37+G-2 (combined) & Pink & 0.520 & 0.024 \\
G-33 & Spotless & 0.606 & 0.060 \\
\multicolumn{3}{c}{ * Binomial standard deviation. }
\end{tabular}

flowering season are based on sample sizes of 1081 for G-30, 241 for G-2, 132 for G-37 and 66 for G-33. There is an indication that pink G-2 outcrosses at a higher rate than pink G-37 but when the two are combined the mean of 0.52 is not significantly different from the 0.48 for wild-type G-30. Consequently, the female outcrossing differential, $k$, was set at unity for the analysis of Populations 1, 2 and 3. In spotless G-33, on the other hand, female outcrossing appears to be higher than in wild-type G-30. Unfortunately the standard error is large and the difference between spotless and wild-type only borders on significance. We assumed this difference to be real because (1) the parent from which G-33 was derived gave an almost identical estimate of 0.605 from 38 progeny sampled in nature, and (2) G-33 was consistently the least autofertile genetic stock in greenhouse plantings. Thus, on the basis of these estimates, the female outcrossing differential, $k$, for the blue spotless comparison in Population 4, was set at 0.79.

Estimates of $\alpha, \beta$ and $m$ are shown for different sampling dates in Populations 1, 2 and 3 (tables 3, 4 and 5). Approximate standard errors based on derivations of Harding and Tucker (1969) are given in brackets with the $\alpha$ and $m$ estimates. These standard errors take binomial frequency as well as sample size into account. The sample distribution for $\beta$ is not known. Both female and male outcrossing values show an irregular tendency 
TABLE 3

Estimates of $\alpha, \beta$ and $\mathrm{m}$ in Population 1

\begin{tabular}{ccccc} 
Sampling & & \multicolumn{2}{c}{$\hat{\beta}$} & \\
date & $\hat{\alpha}$ & $\begin{array}{c}\text { in } \\
\text { blue-flowered } \\
\text { G-30 }\end{array}$ & $\begin{array}{c}\text { in } \\
\text { pink-flowered } \\
\text { G-37 }\end{array}$ & $\hat{m}$ \\
$5 / 27$ & $0.600(0.055)$ & 0.726 & 0.257 & $0.130(0.043)$ \\
$5 / 31$ & $0.289(0.033)$ & 0.407 & 0.112 & $0.184(0.067)$ \\
$6 / 3$ & $0.208(0.083)$ & 0.344 & 0.000 & 0.000 \\
$6 / 10$ & $0.185(0.045)$ & 0.298 & 0.028 & $0.069(0.072)$ \\
$6 / 18$ & $0.432(0.039)$ & 0.539 & 0.260 & $0.301(0.079)$ \\
Total & $0.370(0.021)$ & 0.496 & 0.160 & $0.193(0.035)$
\end{tabular}

Figures in parentheses are standard errors.

TABLE 4

Estimates of $\alpha, \beta$ and $\mathrm{m}$ in Population 2

\begin{tabular}{lcccc} 
Sampling & & \multicolumn{3}{c}{$\hat{\beta}$} \\
date & $\hat{\alpha}$ & $\begin{array}{c}\text { in } \\
\text { blue-flowered } \\
\text { G-30 }\end{array}$ & $\begin{array}{c}\text { in } \\
\text { pink-flowered } \\
\text { G-2 }+ \text { G-37 }\end{array}$ & $\hat{m}$ \\
$4 / 4$ & $0.321(0.045)$ & 0.372 & 0.261 & $0.597(0.189)$ \\
$4 / 14$ & $0.305(0.039)$ & 0.419 & 0.134 & $0.215(0.061)$ \\
$4 / 28$ & $0.375(0.026)$ & 0.500 & 0.166 & $0.198(0.041)$ \\
$5 / 2$ & $0.298(0.028)$ & 0.408 & 0.137 & $0.231(0.059)$ \\
$5 / 8$ & $0.288(0.029)$ & 0.356 & 0.209 & $0.462(0.104)$ \\
$5 / 15$ & $0.538(0.032)$ & 0.603 & 0.447 & $0.533(0.121)$ \\
$5 / 22$ & $0.444(0.044)$ & 0.530 & 0.319 & $0.414(0.084)$ \\
Total & $0.349(0.012)$ & 0.430 & 0.198 & $0.327(0.024)$
\end{tabular}

Figures in parentheses are standard errors.

TABLE 5

Estimates of $\alpha, \beta$ and $\mathrm{m}$ in Population 3

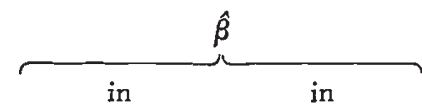

\begin{tabular}{ccccc} 
Sampling & \multicolumn{5}{c}{$\begin{array}{c}\text { blue-flowered } \\
\text { date }\end{array}$} & $\hat{\alpha}-30$ & $\begin{array}{c}\text { pink-flowered } \\
\text { G-2 }+ \text { G-37 }\end{array}$ & $\hat{m}$ \\
$4 / 4$ & $0.584(0.165)$ & 0.729 & 0.106 & $0.044(0.026)$ \\
$4 / 17$ & $0.378(0.072)$ & 0.549 & 0.000 & 0.000 \\
$4 / 23$ & $0.381(0.102)$ & 0.504 & 0.178 & $0.213(0.212)$ \\
$5 / 3$ & $0.364(0.078)$ & 0.495 & 0.143 & $0.170(0.168)$ \\
$5 / 18$ & $0.382(0.083)$ & 0.553 & 0.000 & 0.000 \\
& & & & \\
Total* & $0.370(0.049)$ & 0.512 & 0.110 & $0.118(0.083)$
\end{tabular}

Figures in parentheses are standard errors.

* Tests of $4 / 4$ and $4 / 17$ are not included since numbers of blue and pink flowers were unequal.

to decline through the season in Population 1 and to rise in Population 2. These patterns reflect observed changes in flowering abundance and pollinator density in the two plots. In all 17 tests estimates of $m$, the gametophytic selective values for pink-flowered G-2 and G-37, were much below 
$1 \cdot 0$, the value set for wild-type G-30. In Population 1 an overestimate of $\alpha$ due to the exclusive use of G-37 may have lowered the $m$ value relative to the other populations. In all cases, the male outcrossing frequency, $\hat{\beta}$, was higher than the female outcrossing frequency, $\hat{\alpha}$, in the wild-type, while $\hat{\beta}$ was lower than $\hat{\alpha}$ in the pink-flowered genotype. In the mutant form pink this deficiency in male outcrossing leads to a reduction in total outcrossing.

The $\alpha, k \alpha, \beta$ and $m$ estimates for the components of Population 4 are presented in table 6 . Seed collected from the spotless stock was in all tests

TABLE 6

Estimates of $\mathrm{k} \alpha, \alpha, \beta$ and $\mathrm{m}$ in Population 4

\begin{tabular}{|c|c|c|c|c|c|}
\hline $\begin{array}{l}\text { Sampling } \\
\text { date }\end{array}$ & $\begin{array}{c}k \hat{\alpha} \\
\text { in spotted } \\
\text { G-30 }\end{array}$ & $\begin{array}{c}\hat{\alpha} \\
\text { in spotless } \\
\text { G-33 }\end{array}$ & $\begin{array}{c}\text { in spotted } \\
\mathrm{G}-30\end{array}$ & $\begin{array}{c}\text { in spotless } \\
\mathrm{G}-33\end{array}$ & $\hat{m}$ \\
\hline $4 / 22$ & $0.182(0.099)$ & $0.230(0.125)$ & 0.285 & $0 \cdot 100$ & $0.264(0.403)$ \\
\hline $5 / 3$ & $0.459(0.032)$ & $0.581(0.040)$ & 0.637 & $0 \cdot 177$ & $0.095(0.040)$ \\
\hline $5 / 9$ & $0.450(0.061)$ & $0.569(0.077)$ & $0 \cdot 615$ & 0.246 & $0.160(0.092)$ \\
\hline $5 / 20$ & $0.488(0.082)$ & $0.618(0.103)$ & 0.666 & $0 \cdot 180$ & $0.082(0.031)$ \\
\hline $5 / 25$ to $6 / 13$ & $0.597(0.099)$ & $0.755(0.125)$ & 0.753 & $0 \cdot 323$ & $0.099(0.092)$ \\
\hline Total & $0.457(0.024)$ & $0.579(0.031)$ & 0.632 & $0 \cdot 195$ & $0.109(0.035)$ \\
\hline
\end{tabular}

Figures in parentheses are standard errors.

less than 40 per cent. of that developing from an approximately equal number of exposed flowers of the wild-type stock. Selection against gametophytes of both sexes was thus indicated in G-33, as well as reduced fitness of both outcrossing and selfing pollen. Low values of $m$ could partly be the result of reduced self-compatibility and thus reduced homogeneous outcrosses. However, estimates of $m$ were based on heterogeneous outcrosses, so that all male outcrossing seems to be extremely reduced in this genotype. In this population, as in Populations 1, 2 and 3, male outcrossing in wild-type form G-30 was consistently higher than female outcrossing.

The results of more or less parallel female outcrossing tests of wild-type line G-30 as a minority planting in blue-flowered Populations 5 and 6 and in pink-flowered Population 7 are presented in table 7 . The blue- and

TABLE 7

Comparisons of female outcrossing for rare blue-flowered $G$-30 in homogeneous blue-flowered Populations 5 and 6 and in homogeneous pink-flowered Population 7

Female outcrossing estimates

\begin{tabular}{|c|c|c|c|c|c|}
\hline \multirow[b]{2}{*}{$\begin{array}{l}\text { Sampling } \\
\text { date }\end{array}$} & \multirow{2}{*}{$\begin{array}{c}\text { in blue } \\
\text { population }\end{array}$} & \multicolumn{2}{|c|}{ in pink population } & \multicolumn{2}{|c|}{ Population ratio } \\
\hline & & total & $\begin{array}{l}\text { excluding } \\
\text { migrants }\end{array}$ & total & $\begin{array}{l}\text { excluding } \\
\text { migrants }\end{array}$ \\
\hline $4 / 22$ & $0.269(0.069)$ & $0 \cdot 143(0 \cdot 124)$ & $0 \cdot 143(0 \cdot 124)$ & $0.532(0.465)$ & $0.532(0.465)$ \\
\hline $5 / 20$ & $0.453(0.048)$ & $0.241(0.029)$ & $0.207(0.075)$ & $0.532(0.184)$ & $0.457(0.173)$ \\
\hline $5 / 28$ & $0.473(0.041)$ & $0.567(0.052)$ & $0.522(0 \cdot 053)$ & $1 \cdot 200(0 \cdot 151)$ & $1 \cdot 104(0 \cdot 146)$ \\
\hline $6 / 2$ & $0.590(0.038)$ & $0.548(0.054)$ & $0.440(0.054)$ & $0.929(0.110)$ & $0.746(0.104)$ \\
\hline $6 / 10$ & $0.696(0.033)$ & $0.525(0.064)$ & $0.311(0.059)$ & $0.754(0.099)$ & $0.477(0.088)$ \\
\hline Total & $0.506(0.017)$ & $0.484(0.030)$ & $0.386(0.029)$ & $0.956(0.067)$ & $0.763(0.063)$ \\
\hline
\end{tabular}

Figures in parentheses are standard errors. 
pink-flowered plots were only partly isolated from each other and progeny of G-30 plants tested in the pink-flowered plot contained hybrids to migrant pollen from the neighbouring blue-flowered plot. These hybrids could be distinguished from hybrids derived from pink-flowered pollen donors by one of the seed-coat markers. Late-season estimates and mean estimates in the two pollen-donor frames approach each other, and the population ratio of outcrossing in the pink to outcrossing in the blue background is near unity. This would indicate considerable immunity to population effects using line G-30 as the female tester. On the other hand, when crosses to migrant pollen are excluded from estimates of outcrossing in the pink Population 7, outcrossing values in the two backgrounds diverge from each other and the population ratio drops much below 1.0. This corroborates the notion of selection against outcrossing pollen of the pink-flowered donor, irrespective of local predominance of either the mutant or the wild-type form. However, selection does appear to be more extreme within bipartite populations, as measured by $m$, than between monocoloured populations flowering in close proximity, as measured by the population ratio.

\section{Assumptions}

(1) The experiments were designed to test the effects of flower colour and pattern on male and female outcrossing rate. Male outcrossing in the spotless and pink-flowered forms was less than male outcrossing in the wildtype stock. But other differences between these stocks may have contributed to differences in outcrossing. Mean values for some characters related to outcrossing are presented in table 8 . The wild-type stock, G-30, has smaller

TABLE 8

Characters related to outcrossing

\begin{tabular}{lccccc} 
& \multicolumn{5}{c}{ Genetic stock } \\
\cline { 2 - 4 } \multicolumn{1}{c}{ Character } & $\begin{array}{c}\text { G-30 } \\
\text { wild-type }\end{array}$ & $\begin{array}{c}\text { G-37 } \\
\text { pink }\end{array}$ & $\begin{array}{c}\text { G-2 } \\
\text { pink }\end{array}$ & $\begin{array}{c}\text { G-33 } \\
\text { spotless }\end{array}$ & $\begin{array}{c}\text { Standard } \\
\text { error }\end{array}$ \\
Wing length (mm.) & $9 \cdot 34$ & $11 \cdot 20^{*}$ & $11 \cdot 10^{*}$ & $10 \cdot 00^{*}$ & $0 \cdot 17$ \\
Banner height (mm.) & $5 \cdot 60$ & $7 \cdot 00^{*}$ & $6 \cdot 80^{*}$ & $6 \cdot 50^{*}$ & $0 \cdot 20$ \\
Pollen grains/flower & 12,460 & 12,293 & 12,363 & 12,733 & 865 \\
Ovules/ovary & $5 \cdot 68$ & $5 \cdot 03^{*}$ & $5 \cdot 85$ & $6 \cdot 47 *$ & $0 \cdot 10$ \\
Autofertility & $10 \cdot 87$ & $23 \cdot 41^{*}$ & $17 \cdot 47^{*}$ & $4 \cdot 22^{*}$ & heterogeneous \\
& $(1 \cdot 35)$ & $(3 \cdot 04)$ & $(1 \cdot 50)$ & $(1 \cdot 19)$ &
\end{tabular}

Pollen counts based on method by Traynor (1967). Standard errors in parenthesis are square roots of Error Mean Squares. For autofertility estimates individual standard errors were used.

* Differs significantly from G-30 at 0.05 level.

flowers and, significantly, produces no more pollen than the mutant stocks. If flower size has a value in the attraction of pollinators, the mutants, not wild-type, are at an advantage in this study. In spite of significantly unequal ovule numbers in competing genotypes, as shown in the table, the number of available female gametes in a test component was assumed to be proportional to flower number. This assumption was made when no correlation was found between ovule number per flower and seeds per raceme (Horovitz, 1969). The autofertility estimates suggest only a partial correlation with 
outcrossing rates. These estimates are based on seeds produced per raceme in the absence of pollinators or manipulation. The very low autofertility of spotless G-33 could well explain its high female outcrossing rate, but does not explain its low male outcrossing rate. The high autofertility of the pink mutants could lead a reduced female outcrossing rate but that was not the case; only male outcrossing was reduced in pinks.

Other character differences were not subjected to tests. For example, male gametophytic selection may have occurred after pollen reached the stigma. The assumption that selection occurred during the mobile phase is supported by some direct observations of preferential bee visits to the blueflowered form. Moreover, there was a one-way pollen migration from the homogeneous blue-flowered population to the homogeneous pink-flowered population.

(2) The estimates of female outcrossing for the genetic stocks (table 2) were obtained from test plants grown in homogeneous plantings. These results were then used in the analysis of heterogeneous bipartite plantings. It was assumed that pollinators respond to a flower colour independently of the frequency of the flower colour in the population. This interaction has been studied in Phlox which is pollinated by butterflies (Levin and Kerster, 1970). However, there is an indication that errors in our assumption may not seriously bias the results. Outcrossing estimates for blue-flowered G-30 at parallel sampling dates at Davis, 1968, in a mixed blue and pink-flowered planting (table 4) and in an entirely blue-flowered planting were not significantly different.

(3) An assumption implicit in this study is that results from a uniform experimental planting can be generalised to apply to natural populations. Female outcrossing estimates in the experimental populations were 0.52 for pink mutants, 0.48 for the wild-type, and $0.37,0.35$ and 0.37 for combined pinks and wild-type (tables 2, 3, 4 and 5). Female outcrossing in nature (Harding, 1970) for the Mace Population that gave rise to the stocks G-30 G-2 and G-37 was estimated at $0.43,0.35,0.56$ and 0.43 . It should be pointed out, however, that outcrossing varies greatly from population to population in nature (Harding and Horovitz, 1969; Harding, 1970) and such agreement cannot always be expected. Furthermore, there is no evidence on the rates of male outcrossing in nature.

\section{Discussion}

Quantitative differences in female and male functioning of hermaphrodite individuals have received little attention. The reason may be our categorical approach to the study of sexual systems rather than the rare occurrence of inequalities. Cases in point were described by Darwin (1877), but they were presented as examples of stages in the conversion of hermaphrodite into dioecious plants (e.g. Pulmonaria angustifolia, Euonymus europaeus). Not all categories of absence or presence of a sex are equally well represented in nature. As noted by Darwin (ibid.) gynodioecism in which female and hermaphrodite individuals exist together is common, but androdioecism is rare. Species which have a male and hermaphrodite component are usually polygamous and have a third, exclusively female component. Darwin stressed that male steriles in gynodioecious populations are usually more fertile than hermaphrodites. It was less succinctly stated that the latter in 
turn have to be better male than female parents. In an androdioecious system hermaphrodites would have to furnish an excess of embryo sacs for fertilisation by the separate male component. The rarity of antrodioecism could imply that hermaphrodites are more flexible in their male than in their female output.

When partial selfing enters into thesystem, female functioning also becomes flexible to the extent to which different selfing rates alter the availability of female gametes for cross-fertilisation. In the experimental populations that have been described, genotypes that function largely as outcrossers but are unisexual in their outcrossing phase become feasible theoretically. Such forms would act as hermaphrodites only on rare occasions of selffertilisation. These occasional hermaphrodites could be as important in maintaining a hybridity optimum in a population as are male-sterile forms in gynodioecious populations (Lewis, 1941; Jain, 1961).

Selection as demonstrated in the present 22 tests affected the male phase. The possible trend towards increased selfing in the material studied may

TABle 9

Estimates of female outcrossing $\alpha$ and male outcrossing $\beta$ in populations of Phaseolus lunatus studied by Harding and Tucker (1969)

$\begin{array}{lccc}\text { Population and genotype } & \hat{m} & \hat{\alpha} & \hat{\beta} \\ \begin{array}{l}\text { Population 5, Davis } \\ \text { L-151 }\end{array} & 0.241 & 0.159 & 0.103 \\ \text { L-156 } & 1.000 & 0.179 & 0.330 \\ \text { L-186 } & 0.673 & 0.473 & 0.326 \\ \text { Population 6, Davis } & & & \\ \quad \text { L-63 } & 1.000 & 0.094 & 0.175 \\ \text { L-139 } & 0.313 & 0.135 & 0.065 \\ \text { L-153 } & 0.147 & 0.052 & 0.014 \\ \text { Population 6, Irvine } & & & \\ \text { L-63 } & 1.000 & 0.048 & 0.104 \\ \text { L-139 } & 0.654 & 0.076 & 0.065 \\ \text { L-153 } & 0.518 & 0.091 & 0.053\end{array}$

provide a clue to particularly keen competition among outcrossing male gametophytes. Residual pollen abundance in recent partial selfers could result in an excess which is no longer consumed by pollinating insects. Flowers in this material remained a pollen source through repeated bee trippings. Conceivably, fertilisation can be complete before a flower has dispersed its entire effective pollen. Wastage of such excess pollen could ultimately lead to selection for reduced pollen production. Yet forms whose fitness value of outcross pollen is genotypically high could succeed in perpetuating the trait of high pollen production.

Higher male than female outcrossing in the wild-type in experimental populations may also have occurred because wild-types were tested in competition with mutant forms that are rare in nature. It is possible that, under natural competition with similarly fit pollen donors, male outcrossing in the wild-type stock would have remained confined within the limits of its female outcrossing. However, unequal male and female functioning is also evident from other experiments. To illustrate this, populations of Phaseolus lunatus studied by Harding and Tucker (1969) are cited. In table 9 estimates of the female outcrossing frequency, $\alpha$, are presented together with values of 
male outcrossing, $\beta$, that can be derived from these authors' data. In populations composed of three forms each, divergences between $\alpha$ and $\beta$ are greatest in the forms that compete successfully in their male gametophytic phase, viz. L-156 and L-63.

There are numerous situations in which female and male outcrossing within a genotype become unequal and these are not exhausted by differential selection between the sexes. They can also arise in the absence of selection as a result of unequal female outcrossing between genotypes. At least in theory there are more avenues to unequal than to equal female and male outcrossing. Among the nine alternatives listed for a bipartite population in table 10, there are only three situations in which the two sexes in a form can

TABLE 10

Differences between $\alpha$ and $\beta$ within a genotype resulting from the joint effects of male gametophytic selection between genotypes $A$ and $B$ in the outcrossing phase and differential female outcrossing

\begin{tabular}{|c|c|c|c|}
\hline \multirow[b]{2}{*}{$\begin{array}{c}\text { Female } \\
\text { outcrossing }\end{array}$} & \multicolumn{3}{|c|}{$\begin{array}{l}\text { Male gametophytic selection } \\
\text { in outcrossing phase }\end{array}$} \\
\hline & $\begin{array}{l}\text { Genotype A } \\
\text { selected }\end{array}$ & $\begin{array}{l}\text { Genotype B } \\
\text { selected }\end{array}$ & $\begin{array}{l}\text { No } \\
\text { selection }\end{array}$ \\
\hline$\alpha_{A}=\alpha_{B}$ & $\begin{array}{c}(1) \\
\alpha<\beta \text { in } A \\
\text { and } \\
\alpha>\beta \text { in } B\end{array}$ & $\begin{array}{c}(2) \\
\alpha>\beta \text { in } A \\
\text { and } \\
\alpha<\beta \text { in } B\end{array}$ & $\begin{array}{c}\alpha=\beta \text { in } A \\
\text { and } \\
\alpha=\beta \text { in } B\end{array}$ \\
\hline$\alpha_{A}>\alpha_{B}$ & $\begin{array}{c}\alpha \leqq \text { in } A \\
\text { and } \\
\alpha \leqq \beta \text { in } B\end{array}$ & $\begin{array}{c}(5) \\
\alpha>\beta \text { in } A \\
\text { and } \\
\alpha<\beta \text { in } B\end{array}$ & $\begin{array}{c}(6) \\
\alpha>\beta \text { in } A \\
\text { and } \\
\alpha<\beta \text { in } B\end{array}$ \\
\hline$\alpha_{A}<\alpha_{B}$ & $\begin{array}{c}(7) \\
\alpha<\beta \text { in } A \\
\text { and } \\
\alpha>\beta \text { in } B\end{array}$ & $\begin{array}{l}\alpha \sum_{\text {and }}^{(8)} \text { in } \mathrm{A} \\
\alpha \lesssim \beta \text { in } \mathrm{B}\end{array}$ & $\begin{array}{c}(9) \\
\alpha<\beta \text { in } A \\
\text { and } \\
\alpha>\beta \text { in } B\end{array}$ \\
\hline
\end{tabular}

be quantitatively equal in outcrossing, viz. no selection where the two genotypes outcross equally on the female side (3) and selection for the genotype which outcrosses more highly on the female side (4) and (8). Even in these cases differences will result unless the effects of male selection are exactly balanced by the effects of differential female outcrossing.

In Fig. 1 male outcrossing values in competing forms $\mathrm{A}$ and $\mathrm{B}$ are presented as functions of female outcrossing $k \alpha$ and $\alpha$, respectively. The dependence of male outcrossing on female outcrossing is illustrated in these graphs. For example, the male outcrossing in form A cannot reach 100 per cent. unless $k$, the female outcrossing differential, is $1 \cdot 0$, as in cases 1 and 2. The graphs on the left-hand side of fig. 1 illustrate selection against outcrossing pollen from form B. In case 1 female outcrossing is the same for both forms, as was the situation in the pink- and blue-flowered bipartite populations. In cases 3 and 5 , form $\mathrm{A}$ as compared to form $\mathrm{B}$ is more highly self-fertilised as a female and is more fit as a male in outcrossing.

In the graphs on the right-hand side of fig. 1 , the situation is reversed by considering $m$ greater than 1.0 . The divergences between $\beta_{A}$ and $\beta_{B}$ increase as the value of $k$ deviates from $1 / m$. At $k=1 / m$ (case 4 ) the two functions follow a unit slope in which female outcrossing and male outcrossing 


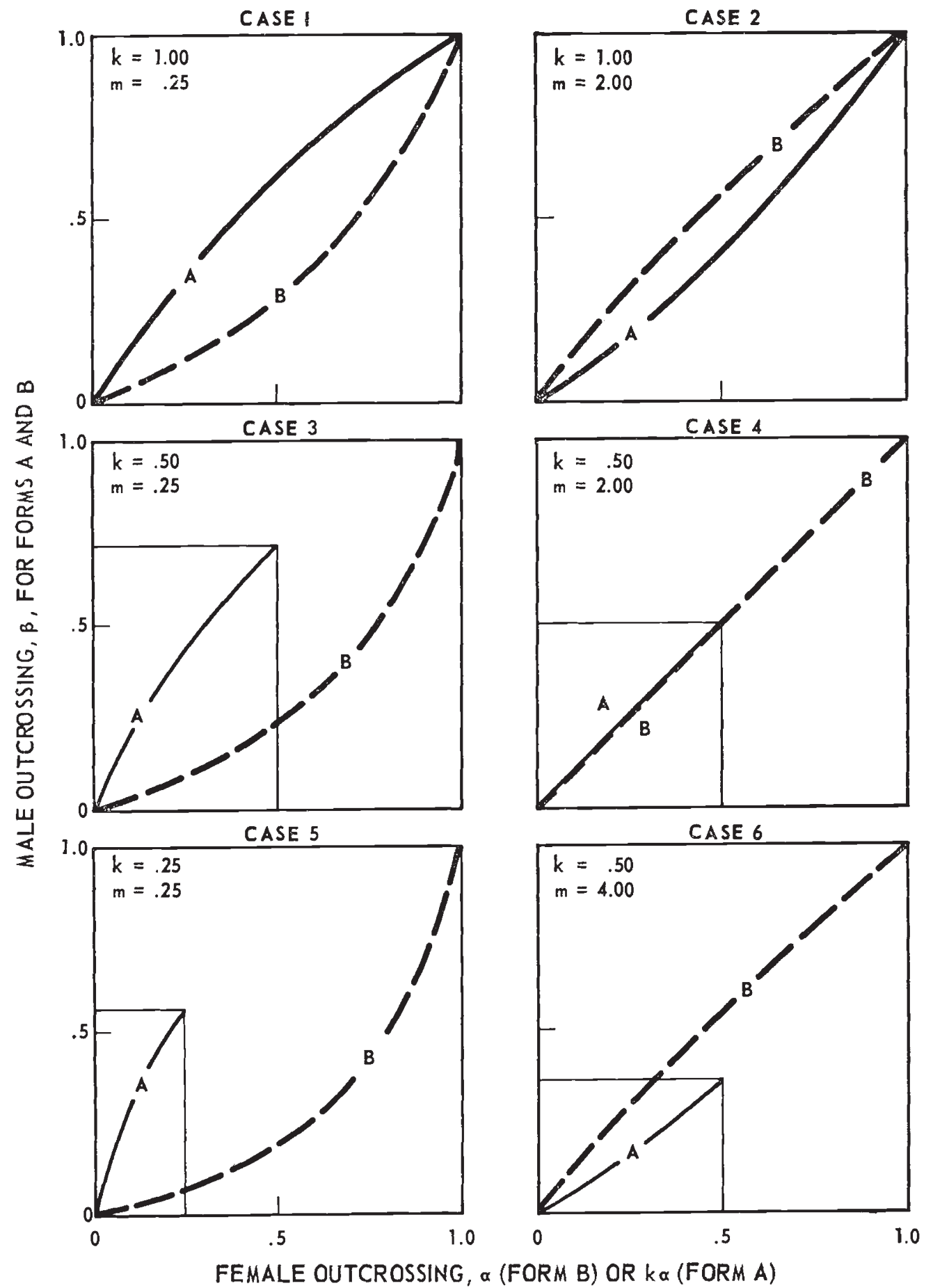

FIG. 1.-Male outcrossing as a function of female outcrossing in competing forms $A$ and $B$ under different $k$ and $m$ values. 
are equal within each form. This relation can also arise in situations (4) and (8) of table 10. In cases 4 and 6 of fig. 1 low female outcrossing in A can limit the availability of female gametophytes to be cross-fertilised by $\mathbf{B}$ and thus reduce male outcrossing in B. A trend towards such a situation was inferred by Crosby (1949) for populations of Primula vulgaris. At least in theory, pollen from thrum individuals can be put at a selective disadvantage by the presence of homostyle individuals which selfed at higher rates than the thrum heterostyles and arrested the spread of the latter as male parents.

In the model employed, the effect of $k$ on female outcrossing is nonanalogous with that of $m$ on male outcrossing. Moreover, parameter $k$ aids to determine both female and male outcrossing, while $m$ affects only male outcrossing. These more far-reaching effects of $k$ than of $m$ fit the biological situation in which female gametes are regarded as a limiting factor to pollen use.

\section{Selection theory}

Recursive selection resulting from nonreciprocal male and female outcrossing is given by

$$
\begin{aligned}
& D^{t+1}=(1-\alpha)\left(D^{t}+H^{t} / 4\right)+\alpha(1-q \text { ᄋ })(1-q \widehat{\jmath}) \\
& H^{t+1}=(1-\alpha) H^{t} / 2+\alpha q(1-q \hat{\jmath})+\alpha q \widehat{\jmath}(1-q \text { 市 }) \\
& R^{t+1}=(1-k \alpha)\left(R^{t}+H^{t} / 4\right)+k \alpha q \text { ᄋ } q \hat{\sigma}
\end{aligned}
$$

where recessives, in frequency $R$, outcross at $k \alpha$, and dominant homozygotes, in frequency $D$, and heterozygotes, in frequency $H$, outcross at $\alpha$. The superscript denotes the transition from generation $t$ to $t+1$. The frequency of recessive male gametophytes in the outcrossing fraction is given by

where

$$
q=m q /(1-q+q m)
$$

$$
q=R+H / 2 \text {. }
$$

The progression of such selection against a recessive allele through 15 sporophytic generations is illustrated in fig. 2 for an $m$ value in the recessive form of $0 \cdot 200$, and a $k$ value of $1 \cdot 0$. Recursive selection is shown for two female outcrossing values. The reason for the more severe selection against the recessive allele under $\alpha=0.50$ than under $\alpha=0.25$ (fig. 2) is that male gametophytic selection occurs only in the outcrossing phase. In this type of selection, in contrast so frequently cited cases of sporophytic selection, the recessive allele is maintained for a longer duration under higher than under lower selfing rates.

\section{Summary}

1. The reproductive system of partially self-fertilising sporophytes in higher plants is usually defined by the extent to which their female gametes unite with foreign male gametes. This female outcrossing does not necessarily reflect the behaviour of male gametes produced by a particular sporophyte. A mathematical model which allows for quantitative comparisons between separate parameters of male and female outcrossing is presented. 


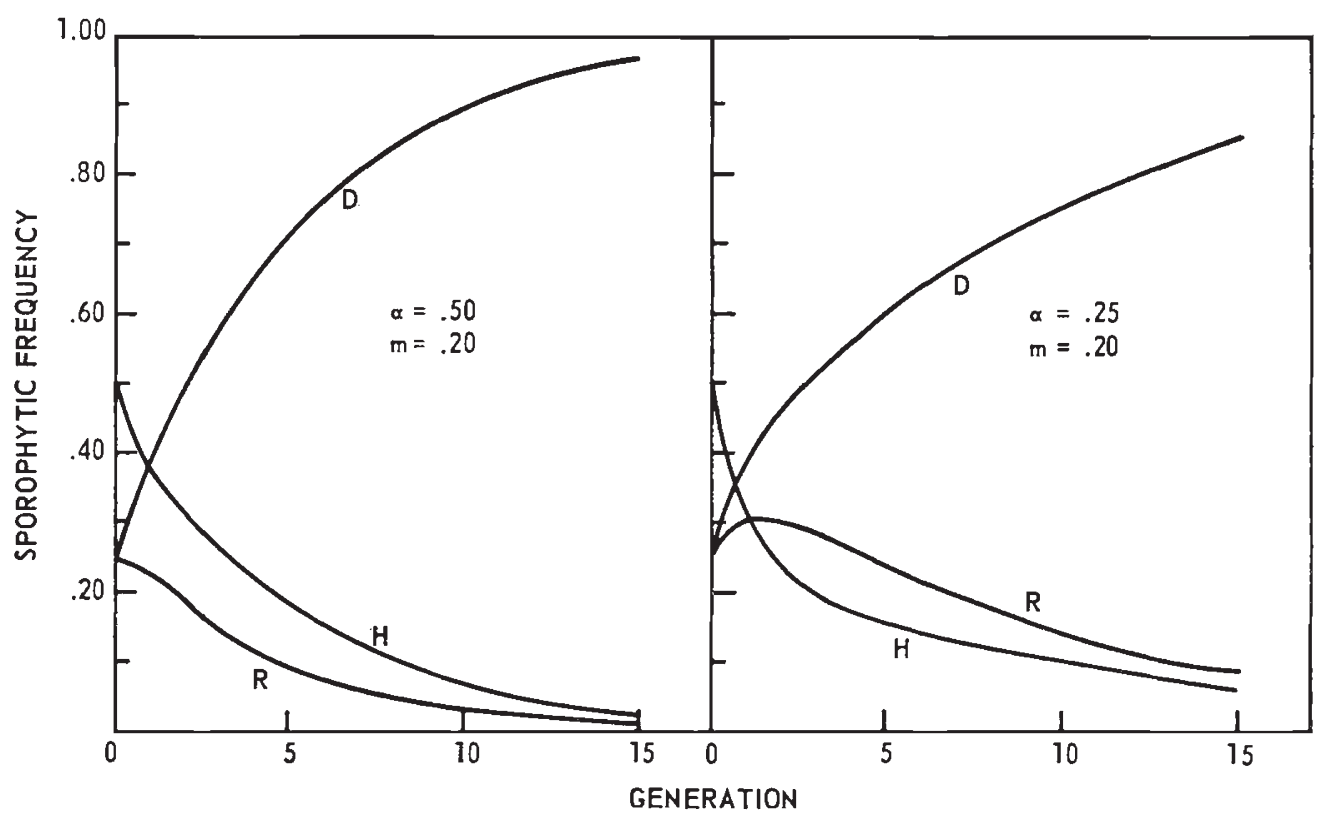

Fig. 2.-Expected frequency curves for genotypes subject to selection between outcrossing male gametophytes.

2. Estimators derived from the general model are applied to results from experimental populations of Lupinus nanus. Through the use of reciprocal genetic markers, the frequencies of male and female outcrossing were estimated in genotypes differing in flower colour and pattern. In each of 22 tests male outcrossing rates in a wild-type blue form were higher than those in mutant pink-flowered or spotless forms. These differences were not reflected in the estimates of female outcrossing, so that female and male rates differed within each form.

3. Transition generation formulae are derived and numerical cases illustrate the effects of selection which result from differential male and female outcrossing. It is shown that selfing can reduce the rate of elimination of an undesirable gene when selection affects male outcrossing gametes.

4. The concept of quantitatively divergent female and male reproductive modes in the same individual is used to emphasise the versatility of hermaphroditism in higher plants.

Acknowledgments.-We are grateful to Dr J. Stamberg for helpful comments on the manuscript.

\section{ReFERENCES}

GROSBY, J. L. 1949. Selection of an unfavorable gene-complex. Evolution, 3, 212-230.

DARwin, c. R. 1877. The Different Forms of Flowers on Plants of the Same Species. J. Murray, London.

DAUMER, K. 1956. Reizmetrische Untersuchungen des Farbensehens der Bienen. Z. vergl. Physiol., 38, 413-478.

HARDING, J. 1970. Genetics of Lupinus. II. The selective disadvantage of the link flower color mutant in Lupinus nanus. Evolution, 24, 120-127. 
HARDING, J., AND TUGKER, G. L. 1964. Quantitative studies on mating systems. I. Evidence for the non-randomness of outcrossing in Phaseolus lunatus. Heredity, 19, 369-381.

HARDING, J., AND MANKINEN, C. B. 1967. Genetics of Lupinus. I. Variations in flower color from natural populations of Lupinus nanus. Can. 7. Bot., 45, 1831-1836.

HARDING, J., AND TUGKER, C. L. 1969. Quantitative studies on mating systems. III. Methods for the estimation of male gametophytic selective values and differential outcrossing rates. Evolution, 23, 85-95.

HARDING, J., AND HOROVITZ, A. 1969. Genetic and environmental variation in the breeding system of Lupinus nanus. Proc. XI Intern. Bot. Congr., Seattle.

HOROVirz, A. 1969. Effect of flower color variations on the mating system in some forms of Lupinus nanus Dougl. (ex Benth.). Ph.D. Dissertation, Univ. of Calif., Davis.

JAIN, s. K. 1961. On the possible adaptive significance of male sterility in predominantly inbreeding populations. Genetics, 46, 1237-1240.

LEVIN, D. A., AND KERSTER, H. w. 1970. Phenotypic dimorphism and populational fitness in Phlox. Evolution, 24, 128-134.

LEWIS, D. 1941. Male sterility in natural populations of hermaphrodite plants. The equilibrium between females and hermaphrodites to be expected with different types of inheritance. New Phytol., 40, 56-63.

MANnING, A. 1956. The effect of honey-guides. Behaviour, 9, 114-139.

MENZEL, R. 1967. Untersuchungen zum Erlernen von Spektralfarben durch die Honigbiene. Z. vergl. Physiol., 56, 22-62.

STEPHENS, S. G., AND FINKNER, M. D. 1953. Natural crossing in cotton. Econ. Bot., 7, 257 269.

TRAYNOR, J. M. 1967. Some nutritional and environmental effects on pollen production and seed viability in alfalfa. M.S. Thesis, Univ. of Calif., Davis.

VASEK, F. C. 1967. Outcrossing in natural populations. III. The Deer Creek population of Clarkia exilis. Evolution, 21, 241-248. 